\title{
Structural organization of long-range GABAergic projection system of the hippocampus
}

\author{
Shozo Jinno* \\ Department of Anatomy and Neurobiology, Graduate School of Medical Sciences, Kyushu University, Fukuoka, Japan
}

\section{Edited by:}

Kathleen S. Rockland, RIKEN Brain

Science Institute, Japan

Reviewed by:

Takehsi Kaneko, Kyoto University,

Japan

Kathleen S. Rockland, RIKEN Brain

Science Institute, Japan

*Correspondence:

Shozo Jinno, Department of Anatomy and Neurobiology, Graduate School of

Medical Sciences, Kyushu University,

3-1-1 Maidashi, Higashi-ku, Fukuoka

812-8582, Japan.

e-mail:sjnno@med.kyushu-u.ac.jp
GABA is a key mediator of neural activity in the mammalian central nervous system, and a diverse set of GABAergic neurons utilize GABA as a transmitter. It has been widely accepted that GABAergic neurons typically serve as interneurons while glutamatergic principal cells send excitatory signals to remote areas. In general, glutamatergic projection neurons monosynaptically innervate both principal cells and local GABAergic interneurons in each target area, and these GABAergic cells play a vital role in modulation of the activity of principal cells. The formation and recall of sensory, motor and cognitive representations require coordinated fast communication among multiple areas of the cerebral cortex, which are thought to be mostly mediated by glutamatergic neurons. However, there is an increasing body of evidence showing that specific subpopulations of cortical GABAergic neurons send long-range axonal projections to subcortical and other cortical areas. In particular, a variety of GABAergic neurons in the hippocampus project to neighboring and remote areas. Using anatomical, molecular and electrophysiological approaches, several types of GABAergic projection neurons have been shown to exist in the hippocampus. The target areas of these cells are the subiculum and other retrohippocampal areas, the medial septum and the contralateral dentate gyrus. The long-range GABAergic projection system of the hippocampus may serve to coordinate precisely the multiple activity patterns of widespread cortical cell assemblies in different brain states and among multiple functionally related areas.

Keywords: GABAergic neuron, long-range projection, hippocampus, medial septum, subiculum, retrosplenial cortex multiregional coordination

\section{INTRODUCTION}

GABA is a key mediator of neural activity in the mammalian central nervous system, and a diverse set of GABAergic neurons utilize GABA as a transmitter. The majority of cortical GABAergic neurons are considered to work as local interneurons. Excitatory glutamatergic projection neurons monosynaptically innervate both principal cells and local GABAergic interneurons in each target area, where GABAergic synaptic inhibition strictly regulates the spatial and temporal extent of neuronal activity. As such, topographically organized GABAergic inputs are essential to regulate sleep, arousal, cognition, locomotion and mood. For instance, a specific subset of GABAergic neurons in the cerebral cortex can be part of the neurobiological substrate that underlies homeostatic sleep regulation (Gerashchenko et al., 2008). In addition, recent studies have emphasized that dysfunctions in the GABAergic system might be associated with various pathological conditions including epilepsy, Parkinson's disease, Alzheimer's disease and mental illness (Kalueff and Nutt, 2007). In particular, increasing evidence suggests the possible involvement of GABA in the neurobiology of mood disorder and the mechanisms of antidepressant action (Gos et al., 2009; Jinno and Kosaka, 2009; Sanacora and Saricicek, 2007).

It has been well established that the formation and recall of sensory, motor and cognitive representations require coordinated communication among multiple areas of the cerebral cortex, which are mostly mediated by long-range glutamatergic projections. Interestingly, a number of studies show that specific subpopulations of cortical GABAergic neurons also send long-range inhibitory projections to subcortical and other cortical areas. For instance, the medial septum is one of the extrahippocampal targets of a subset of GABAergic neurons in the hippocampus (Alonso and Köhler, 1982). The existence of additional remote targets of hippocampal GABAergic neurons, such as subiculum and retrosplenial cortex, has also been demonstrated (Jinno et al., 2007; Losonczy et al., 2002; Miyashita and Rockland, 2007; van Groen and Wyss, 2003). Long-range GABAergic projections have also been described in the isocortex (Fabri and Manzoni, 2004; Gonchar et al., 1995; Jinno and Kosaka, 2004; Tomioka and Rockland, 2007).

Starting with the seminal work of Ramón y Cajal (1911) revealing the morphological features of cortical neurons, many studies reported the diversity of GABAergic interneurons in the cortex based on anatomical, neurochemical and electrophysiological analyses (DeFelipe, 1993; Freund and Buzsáki, 1996; Maccaferri and Lacaille, 2003; Markram et al., 2004). Current evidence indicates that distinct classes of GABAergic neurons specifically coordinate the activity of cortical pyramidal neurons in a spatially and temporally different and brain-state-dependent manner (Klausberger and Somogyi, 2008). In this article, I aimed to summarize the recent findings and outline the structural organization of GABAergic projection system of the hippocampus. 


\section{EXTRA HIPPOCAMPAL TARGETS OF GABAergic PROJECTION SYSTEM OF THE HIPPOCAMPUS}

The diagram of the long-range GABAergic projection system of the hippocampus is schematically summarized in Figure 1. In this section, I describe the diversity of GABAergic neurons projecting to the following major extrahippocampal targets: medial septum, subiculum, retrosplenial cortex and contralateral dentate gyrus (cDG). Using in vivo recording (Jinno et al., 2007), we have previously reported that some of the GABAergic neurons project to multiple areas, such as the medial septum and the subicular area (i.e., double projection cells). Here, I discuss the characteristics of GABAergic neurons innervating each target separately, and then summarize the significance of multiple targeting cells in the following section.

\section{MEDIAL SEPTUM}

The most studied remote target of the hippocampal GABAergic projection neurons is the medial septum (Figure 1). Using intraseptal injection of horseradish peroxidase as the retrograde tracer, Alonso and Köhler (1982) found that a subset of GABAergic neurons of

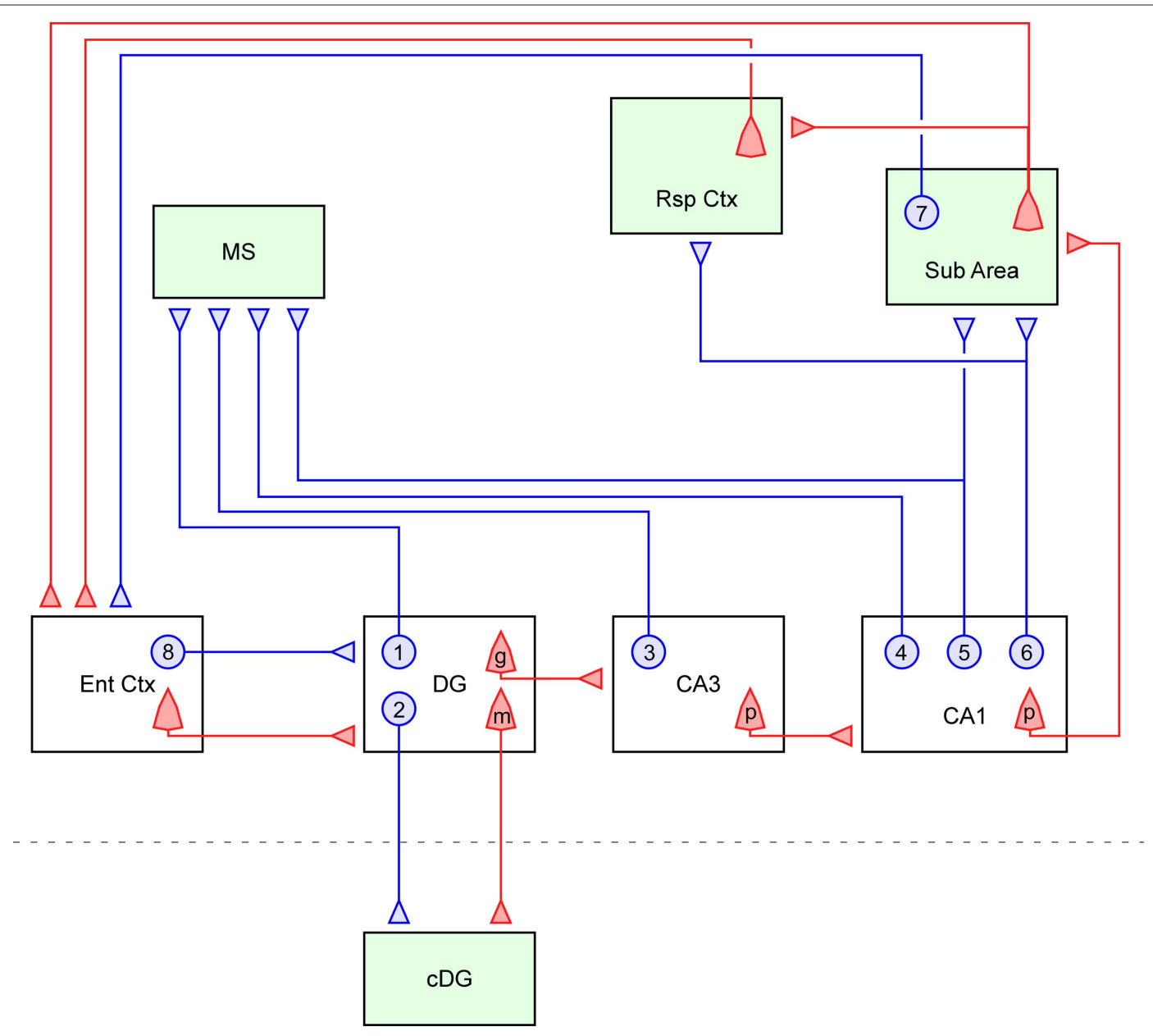

FIGURE 1 | Summary diagram of the GABAergic efferents of the hippocampus. The long-range GABAergic projection system (blue) and major glutamatergic circuit (red) of the hippocampus and related limbic structures are schematically described. Four extrahippocampal targets are colored in green: medial septum (MS), subiculum (Sub Area), retrosplenial cortex (Rsp $\mathrm{Ctx}$ ) and contralateral dentate gyrus (cDG). This figure highlights the efferent GABAergic pathway of the hippocampus, and thus its local collaterals and related glutamatergic circuits are only partially described. In the dentate gyrus, some of the hilar GABAergic neurons project to the medial septum (1) and others project to the $\mathrm{CDG}$ via the commissural pathway (2). The existence of GABAergic cells projecting to both the medial septum and the CDG has not been proven. The granule cells ( $g$ ) in the dentate gyrus (DG) send mossy fiber axons to the ipsilateral CA3 area, while hilar mossy cells $(\mathrm{m})$ send commissural axon to the contralateral side of the dentate gyrus. In the CA3 region, GABAergic cells projecting to the medial septum are scattered throughout all the layers (3). Some of the CA3 pyramidal cells (p) project back to the dentate gyrus, but they were omitted from this diagram for simplicity. In the CA1 region, there are three types of GABAergic projection neurons, i.e., those projecting exclusively to the medial septum (4), projecting to both the medial septum and subicular/retrosplenial area (5), and projecting exclusively to the subicular/retrosplenial area (6). In the CA1 region, the pyramidal cells (p) project not only to the subicular area but also to the lateral septum (not shown). In addition to the above hippocampal GABAergic projection neurons, earlier studies have also shown the existence of other interareal GABAergic connections in parallel to the glutamatergic circuits. For instance, the projection from the presubiculum comprises a small inhibitory component from GABAergic neurons (7) and targets entorhinal interneurons (van Haeften et al., 1997). The perforant path that originates from the entorhinal cortex may also have a small GABAergic component (8) in addition to the main glutamatergic projection (Germroth et al., 1989). 
the hippocampus innervate the medial septum (H-MS cells) in the rat brain. The H-MS cells were found in all regions of the hippocampus, but they were distributed in a layer specific manner: in the CA1 region, they were mainly located in the stratum oriens; in the CA3 region, they were scattered throughout all the layers; and in the dentate gyrus (DG), they were exclusively located in the hilar area (Figure 2A, Jinno and Kosaka, 2002; Totterdell and Hayes, 1987).
The morphological characteristics of $\mathrm{H}-\mathrm{MS}$ cells were examined using fixed slice preparations of the rat hippocampus (Schwerdtfeger and Buhl, 1986), and the following cells were identified: stellate cells in the hilus, horizontal basket cells in the stratum oriens of CA1 and CA3, stellate cells in the stratum radiatum of CA3 and pyramid-like cells in the stratum radiatum of CA1. The main postsynaptic targets of H-MS cells in the medial septum were
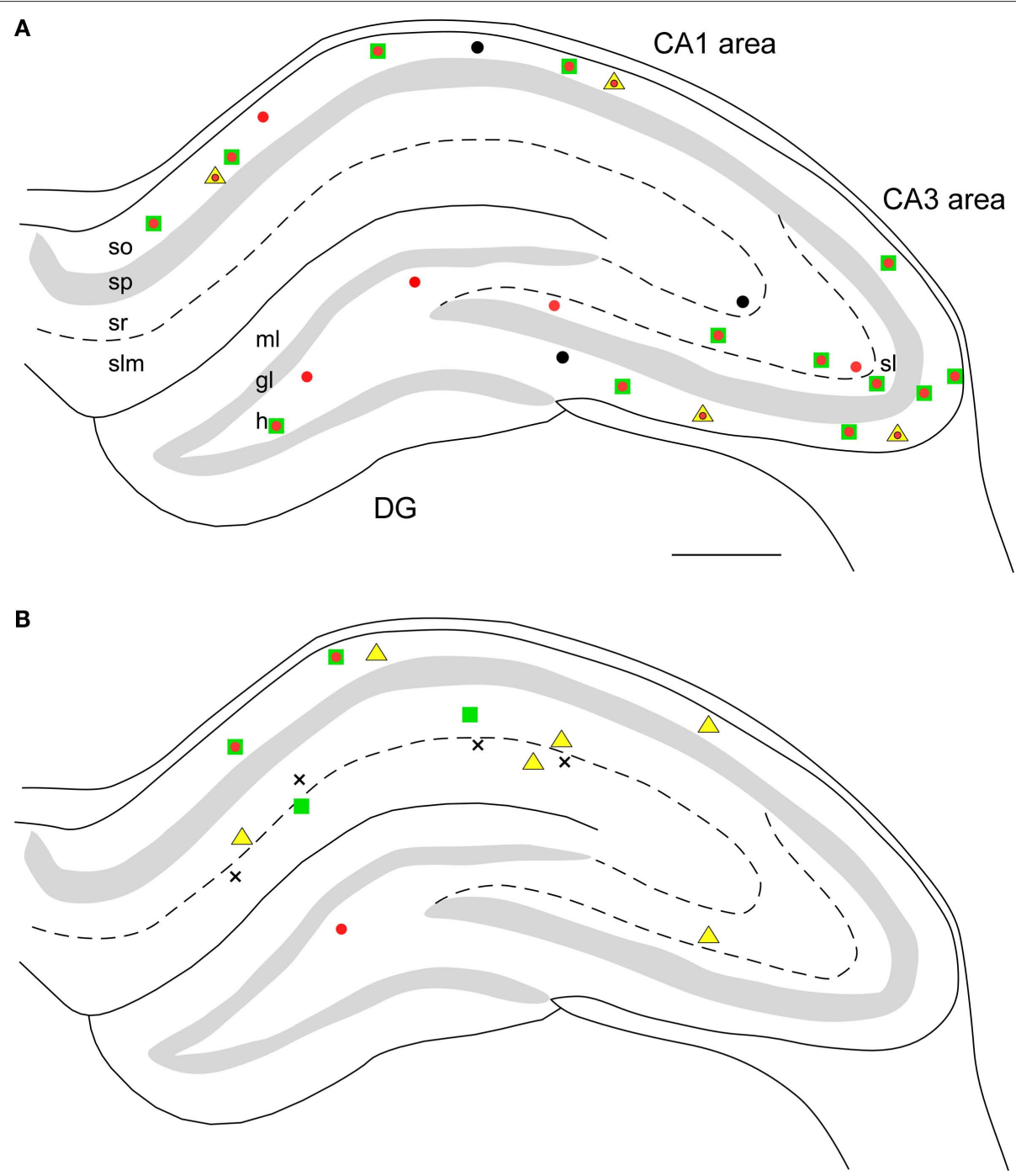

- SOM only; - mGluR1a only; $\triangle \mathrm{M} 2 \mathrm{R}$ only; $\times$ immunonegative for all - SOM + mGluR1a only; $\triangle \mathrm{SOM}+\mathrm{M} 2 \mathrm{R}$ only; $\bullet \mathrm{SOM}+$ mGluR1a + M2R

FIGURE 2 | Distributions of retrogradely labeled GABAergic projection neurons following Fluoro-gold injection into the medial septum $(A)$ or the subiculum (B). Each panel represents a 70- $\mu \mathrm{m}$ thick triple immunofluorescence labeled section for somatostatin (SOM), metabotropic glutamate receptor $1 \alpha$ (mGluR1 $\alpha$ ) and muscarinic acetylcholine receptor type 2 (M2R). (A) The H-MS cells are distributed in all regions of the hippocampus. In the CA1 area, most of them are in the stratum oriens (so). In the CA3 area, they are in the all layers, whereas they are restricted to the hilus ( $h$ ) in the dentate gyrus (DG). Virtually all H-MS cells are SOM-positive, and the majority of them are SOM-positive/ mGluR1 $\alpha$-positive/M2R-negative. In addition, there are also some triple-positive cells and SOM-positive/mGluR1 $\alpha$-negative/M2R-positive cells. (B) The H-Sub cells are mainly present in the CA1 region, and rarely found in the CA3 region and in the dentate gyrus. In the CA1 area, SOM-positive/mGluR1 $\alpha$-positive/ $\mathrm{M} 2 \mathrm{R}$-negative projection cells are mostly detected in the stratum oriens, whereas SOM-negative/mGluR1 $\alpha$-negative/M2R-positive cells are present throughout all layers. In addition, SOM-negative/mGluR1 $\alpha$-positive/ M2R-negative cells are distributed in strata radiatum (sr) and lacunosum-moleculare (slm). There are a few $\mathrm{H}$-Sub cells immunonegative for all three molecules. Scale bar in (A) $=500 \mu \mathrm{m}$ [applies to (A) and (B)]. gl, granule cell layer; $\mathrm{ml}$, molecular layer; sl, stratum lucidum; $\mathrm{sp}$, stratum pyramidale. Panels $(\mathbf{A})$ and $(\mathbf{B})$ are modified and reproduced from Jinno et al. (2007), with permission of the publisher. 
parvalbumin (PV)-expressing GABAergic neurons and, to a lesser extent, cholinergic neurons (Tóth et al., 1993). On the other hand, several studies, employing different methods, have demonstrated conflicting results with regard to the local targets of H-MS cells. In juvenile rats, the local axons of CA1 H-MS cells recorded in vitro were reported to innervate predominantly hippocampal GABAergic neurons (Gulyás et al., 2003). By contrast, the main local targets of in vivo recorded (Jinno et al., 2007) or retrogradely labeled (Takács et al., 2008) GABAergic cells projecting to the medial septum and subiculum were pyramidal neurons in the CA1 area of the adult rats. Although it is difficult to explain the discrepancy, differences in ages of animals and labeling methods might be related to the inconsistent results in local postsynaptic targets of H-MS cells.

The hippocampus also receives GABAergic inputs from the medial septum, and thus the medial septum and the hippocampus are connected reciprocally (Raisman, 1966). The two major components of the septo-hippocampal projection are cholinergic and GABAergic neurons (Köhler et al., 1984; Shute and Lewis, 1963). The cholinergic projection terminates on all types of hippocampal cells (Frotscher and Léránth, 1985), whereas septal GABAergic neurons specifically innervate hippocampal GABAergic neurons (Freund and Antal, 1988; Gulyás et al., 1991). Recently, Takács et al. (2008) demonstrated direct reciprocity by using combined retrograde and anterograde tracing; that is, H-MS cells are the postsynaptic targets of GABAergic septo-hippocampal axons. On the other hand, GABAergic terminals of H-MS cells in the medial septum were shown to innervate septo-hippocampal neurons retrogradely labeled from the ventral hippocampus (Tóth et al., 1993). This reciprocal loop between the hippocampus and the medial septum via GABAergic neurons is considered to play a critical role for generating the rhythmic activity and synchronization (Dragoi et al., 1999; Wang, 2002).

\section{SUBICULUM}

Recent studies have demonstrated the existence of hippocampal GABAergic cells projecting to the subiculum (H-Sub cells; Figure 1). The first hint of a possible projection of GABAergic neurons from the hippocampus to the subiculum was shown by using slice preparations (Losonczy et al., 2002). They found that the oriens-bistratified (O-Bi) cells located in the CA1 region innervated the $\mathrm{CA} 3$ region and the subiculum in juvenile mice. One trilaminar cell recorded in vivo was decorated by metabotropic glutamate receptor $8 \mathrm{a}$ (mGluR8a)-enriched boutons, and exhibited a large projection from the CA1 stratum oriens to the subiculum (Ferraguti et al., 2005).

Using retrograde labeling, the distributions of $\mathrm{H}$-Sub cells were estimated in the rat brain (Figure 2B). Differently from the H-MS cells, the retrogradely labeled $\mathrm{H}$-Sub cells were mainly found in the CA1 region, and only a few cells were detected in the CA3 region and the dentate hilus. In the CA1 region, $\mathrm{H}$-Sub cells were scattered throughout all the layers. The majority of $\mathrm{H}$-Sub cells in the stratum oriens were large-sized horizontal cells, while those in the strata radiatum and lacunosum-moleculare were small to medium-sized bipolar and multipolar cells. The postsynaptic targets of long-range axons in the subiculum were assumed to be pyramidal neurons, although the ratios were not determined due to technical limitations. The major local targets of seven H-Sub cells were the dendritic shafts of pyramidal neurons (Jinno et al., 2007). But, one H-Sub cell expressing enkephalin (ENK) innervated dendritic shafts of GABAergic and pyramidal neurons (Fuentealba et al., 2008). The targets of ENK-expressing H-Sub cells were associated with the location of axonal arbors, i.e., interneurons were the main targets in the alveus, both interneurons and pyramidal cell dendrites were innervated in the other layers, and interneurons were the exclusive targets in the subiculum.

It should be noted that four in vivo recorded cells projected from the CA1 stratum oriens to both the subiculum and the medial septum (Jinno et al., 2007). Thus, there might be three groups of projection neurons in the CA1 region: those sending axons exclusively to the medial septum ( 4 in Figure 1), those innervating both the medial septum and the subicular are (5 in Figure 1), and those exclusively sending axons to the subicular/retrosplenial cortex (6 in Figure 1). Although the cells exclusively projecting to the medial septum (4) have not yet been identified, their existence has been suggested by the numerical data showing that the numbers of retrogradely labeled cells after injection into the medial septum are much larger than those after injection into the subiculum (see Figures 2A,B).

\section{RETROSPLENIAL CORTEX}

A few GABAergic neurons in the CA1 region are identified by injections of retrograde tracers into the retrosplenial cortex (van Groen and Wyss, 2003; Wyss and van Groen, 1992). The majority (about 65\%) of hippocampal GABAergic neurons projecting to the granular retrosplenial cortex ( $\mathrm{H}$-Rsp cells) were detected at the border between strata radiatum and lacunosum-moleculare of the CA1 region, and a smaller population was located in the stratum radiatum (Miyashita and Rockland, 2007). Many fewer cells ( $<10 \%)$ were found in the stratum oriens or stratum pyramidale of the CA1 region. In the CA3 and DG, virtually no cells were retrogradely labeled after the injection of tracer into the granular retrosplenial cortex. It should also be noted that two in vivo recorded cells projected from the CA1 region to the retrosplenial cortex through the subicular area (Jinno et al., 2007). The morphological characteristics of H-Rsp cells at the border of strata radiatum and lacunosummoleculare are rather similar to those of H-Sub cells.

The retrosplenial cortex has been implicated in various functions including spatial navigation and memory (Cain et al., 2006; Keene and Bucci, 2009; Wolbers and Büchel, 2005). There is increasing evidence that the retrosplenial cortex has a close functional relationship with the hippocampus (Burwell and Amaral, 1998; van Groen and Wyss, 2003). Anatomical studies indicate that, in addition to the hippocampal glutamatergic output to the retrosplenial cortex relayed through the subiculum, direct GABAergic projections by $\mathrm{H}$-Rsp cells might play a role in processing of spatial information, but the significance remains to be elucidated.

\section{COMMISSURAL PROJECTION}

A small number of GABAergic neurons in the hilus of the DG have axonal projections to the CDG through the hippocampal commissure (Ribak et al., 1986; Seress and Ribak, 1983). Although the targets of these neurons are not strictly extrahippocampal, hilar GABAergic neurons with commissural projection should logically be included as long-range GABAergic projection neurons. 
The postsynaptic targets of GABAergic commissural projections are thought to be dendrites of granule cells (Deller, 1998). It has not been clearly proven whether the hilar cells innervating the medial septum (1 in Figure 1) simultaneously send commissural axons to the cDG (2 in Figure 1).

\section{NEUROCHEMICAL CHARACTERIZATION OF GABAergic PROJECTION NEURONS IN THE HIPPOCAMPUS}

A number of studies have reported the neurochemical characterization of hippocampal GABAergic projection neurons in combination with tracer labeling. Some of the previously identified molecular markers might be expressed in neurons innervating different target areas, because a given neurochemical marker is not always specifically related to the connectional characteristics (Freund and Buzsáki, 1996). But there is ample evidence for the importance of molecular markers in the classification of GABAergic neurons tested (Jinno and Kosaka, 2006). Thus in this section, I describe the eight major molecules identified so far in GABAergic neurons projecting to the extrahippocampal areas.

Before entering into a detailed discussion, it might be better to briefly argue on a possible species difference in chemical characteristics of GABAergic projection neurons. In the neocortex, there is a considerable difference between mice and rats with respect to the basic microcircuits (DeFelipe et al., 2002). Several species differences have also been reported in the functional organization of the hippocampus. Most notably, glutamatergic hilar mossy cells showed neurochemical discrepancies between mice and rats. The calcium-binding protein calretinin (CR) is expressed in mossy cells in the mouse ventral hilus, but not in the rat hilus (Blasco-Ibáñez and Freund, 1997; Fujise et al., 1998; Liu et al., 1996). On the contrary, calcitonin gene-related peptide is localized in the rat mossy cells, but not in the mouse mossy cells (Freund et al., 1997; Sakurai and Kosaka, 2007). However, interestingly enough, the morphofunctional similarities in hippocampal GABAergic neurons have been repeatedly reported in mice and rats. For example, Mátyás et al. (2004) showed that the neurochemical and morphological classifications of hippocampal GABAergic interneurons established in the rat were largely valid for mouse strains. The numerical densities of chemically defined subpopulations of GABAergic neurons in the mouse hippocampus were comparable to those in the rat hippocampus (Jinno and Kosaka, 2006; Nomura et al., 1997). Taken together, it is possible to hypothesize that the chemical characteristics of GABAergic projection neurons in the rat and mouse hippocampus are rather similar to each other. But I leave the matter open.

\section{SOMATOSTATIN}

Somatostatin (SOM) is a neuroactive peptide, and one of the key molecules of H-MS cells (Zappone and Sloviter, 2001). The vast majority $(93.0 \%)$ of the H-MS cells express SOM in the mouse hippocampus (Jinno and Kosaka, 2002). The percentages were very high both in the Ammon's horn (95.5\% in the CA1 region, $92.6 \%$ in the $\mathrm{CA} 3$ region) and the DG (92.1\%) in the mouse hippocampus. In contrast, one half of SS-positive neuron in the CA3 region (49.6\%) and DG (44.1\%) projected to the medial septum, and $22.5 \%$ in the CA1 region projected to the medial septum. Similar results were obtained from the rat hippocampus.
Using slice preparations of juvenile mice, Losonczy et al. (2002) showed that a large population of O-Bi cells in the CA1 stratum oriens innervating both the $\mathrm{CA} 3$ and subiculum were $\mathrm{SOM}$-positive (7 of 10 cells tested). The patterns of expression of SOM in the $\mathrm{H}$-Sub cells in the rat hippocampus were systematically assessed by retrograde labeling (Jinno et al., 2007). In the CA1 region, 50\% of $\mathrm{H}$-Sub cells were SOM-positive, while no $\mathrm{H}$-Sub cells were immunoreactive for SOM in the strata radiatum and lacunosummoleculare. In the CA3 strata radiatum/lacunosum-moleculare and the dentate hilus, SOM was detected in 43 and $75 \%$ of $\mathrm{H}$-Sub cells, respectively.

In the rat CA1 region, SOM was not detected in H-Rsp cells so far examined (Miyashita and Rockland, 2007). On the other hand, the vast majority (as high as 96\%) of SOM-positive cells project to the contralateral hippocampus via the commissural pathway in the rat dentate hilus (Zappone and Sloviter, 2001). Some of the hilar commissurally projecting GABAergic cells receive cholinergic inputs (Léránth and Frotscher, 1987).

\section{NEUROPEPTIDE $Y$}

Neuropeptide Y (NPY) is a peptide belonging to the pancreatic polypeptide family (Tatemoto et al., 1982). The frequent colocalization of NPY and SOM has been reported in cortical and subcortical cells in the rodent and primate brain (Chan-Palay, 1987; Köhler et al., 1987). Using "mirror" technique, Tóth and Freund (1992) showed that 20\% of H-MS cells were NPY-positive in the rat brain. Regional differences in the expression of NPY in H-MS cells were shown in the rat hippocampus (Jinno et al., 2007). In the Ammon's horn, less than half of $\mathrm{H}-\mathrm{MS}$ cells ( $46 \%$ in the CA1 region, $25 \%$ in the CA3 region) were positive for NPY, whereas virtually all H-MS cells (92\%) in the DG contained NPY. The expression ratios of NPY in H-Sub cells (20\% in the CA1 region, $43 \%$ in the CA3 region, and $80 \%$ in the DG) were generally similar to those in H-MS cells.

The expression of NPY in H-Rsp cells has not yet been established. In the dentate hilar area, a small population $(2 \%)$ of NPY-positive hilar neurons has been reported to project to the contralateral hippocampus via the commissural pathway (Deller and Léránth, 1990). But the percentage might be underestimated due to the limitation of detection sensitivity.

\section{CALBINDIN D28K}

Another key molecule of H-MS cells is calbindin D28K (CB), which belongs to the EF-hand calcium-binding protein family. It has been reported that the majority of $\mathrm{H}-\mathrm{MS}$ cells are $\mathrm{CB}$-positive in the rat hippocampus (Tóth and Freund, 1992). Although the authors did not demonstrate the GABAergic nature of cell bodies of retrogradely labeled CB-expressing H-MS cells, subsequently they showed that the anterogradely labeled terminals in the septum originating from the hippocampus were GABA like-immunoreactive (Tóth et al., 1993). Immunofluorescent multiple labeling showed that $38 \%$ of retrogradely identified $\mathrm{H}-\mathrm{MS}$ cells were $\mathrm{CB}$-positive in the mouse hippocampus (Jinno and Kosaka, 2002). Approximately half of H-MS cells in the Ammon's horn expressed CB (57\% in the CA1 region, $41 \%$ in the CA3 region), while none of them were positive for CB in the DG. Similar results were shown in the rat hippocampus (Jinno et al., 2007). 
Expression ratios of $\mathrm{CB}$ in retrogradely labeled $\mathrm{H}$-Sub cells were generally lower than those in H-MS cells (Jinno et al., 2007). In the $\mathrm{CA} 1$ region, $27 \%$ of $\mathrm{H}$-Sub cells in the stratum oriens expressed $\mathrm{CB}$, and only a few cells (3-4\%) in the strata radiatum and lacunosummoleculare were CB-positive.

$\mathrm{CB}$ was not detected in H-Rsp cells so far examined (Miyashita and Rockland, 2007). Possible expression of CB in commissurally projecting GABAergic neurons has not yet been examined.

\section{PARVALBUMIN}

PV is a low-molecular-weight, high-affinity calcium-binding protein of the EF hand family. Although infrequently, PV is detected in $5-15 \%$ of H-MS cells in the mouse and rat brain (Jinno and Kosaka, 2000; Jinno et al., 2007). PV is also expressed in a small population $(4 \%)$ of H-Sub cells in the rat hippocampus. On the other hand, no H-Rsp cells contained PV (Miyashita and Rockland, 2007). In the DG, the majority (as high as $84 \%$ ) of PV-positive neurons commissurally project to the contralateral hippocampus (Goodman and Sloviter, 1992; Zappone and Sloviter, 2001).

\section{CALRETININ}

$\mathrm{CR}$ is a high affinity EF-hand calcium-binding protein. It is well known that CR is expressed in one of the populations of GABAergic neurons called interneuron-specific (IS) cells, i.e., those exclusively innervating other GABAergic neurons (Gulyás et al., 1999). In addition, CR is also expressed in $18 \%$ of H-MS cells of the rat hippocampus. But, neither $\mathrm{H}$-Sub cells nor $\mathrm{H}$-Rsp cells were positive for CR (Jinno et al., 2007; Miyashita and Rockland, 2007). In the DG, one third of CR-positive GABAergic neurons projected commissurally (Zappone and Sloviter, 2001).

\section{MUSCARINIC ACETYLCHOLINE RECEPTOR TYPE 2}

Acetylcholine (ACh) modulates learning and memory in many tasks through actions in the hippocampus and striatum (Bartus et al., 1982; Gold, 2003). Muscarinic ACh receptor type 2 (M2R) is commonly expressed in a considerable population of H-MS cells (38\%, Hájos et al., 1998) and H-Sub cells (42\%, Jinno et al., 2007) in the rat hippocampus. In contrast, only a smaller subset (14\%) of H-Rsp cells was positive for M2R (Miyashita and Rockland, 2007). It has not been tested whether M2R is expressed in commissurally projecting GABAergic neurons in the dentate hilus.

\section{mGluR1 $\alpha$}

Synergic activation of M2R and mGluRs induces enhancement of burst firing, and is thought to be involved in intrinsic neuronal plasticity (Moore et al., 2009). Expression of mGluR $1 \alpha$ in GABAergic projection neurons was tested in $\mathrm{H}-\mathrm{MS}$ cells and $\mathrm{H}-\mathrm{Sub}$ cells (Jinno et al., 2007). In the Ammon's horn, the majority of H-MS cells expressed mGluR1 $\alpha$ (69\% in the CA1, and $84 \%$ in the CA3 region), whereas only $15 \%$ of $\mathrm{H}-\mathrm{MS}$ cells showed mGluR $1 \alpha$ immunoreactivity in the DG. H-Sub cells also expressed mGluR $1 \alpha$, but the expression ratios were lower ( $40 \%$ in the CA1 region) than those of H-MS cells.

\section{ENKEPHALIN}

In the CA1 area, ENK has been detected in a population of IS cells (Blasco-Ibáñez et al., 1998). In addition, a recent retrograde labeling study showed that ENK was expressed in $11.3 \%$ of $\mathrm{H}$-Sub cells using a highly sensitive viral vector for retrograde labeling (Fuentealba et al., 2008). The ENK-positive H-Sub cells $(n=7)$ were located in the middle and deep stratum radiatum, close to the stratum lacunosum-moleculare. All tested ENK-positive H-Sub cells were co-labeled for the orphan nuclear receptor chicken ovalbumin upstream promoter-transcription factor II, but none for CR.

\section{MULTIREGIONAL COORDINATION BY LONG-RANGE GABAergic PROJECTION NEURONS}

This final section considers the potential significance of long-range GABAergic projection systems both in basic and clinical research. It has been repeatedly described that GABAergic neurons exhibit substantial diversity in their anatomical, neurochemical and electrophysiological characteristics (Markram et al., 2004; Somogyi and Klausberger, 2005). Due to this phenotypic variety, the classification of cortical GABAergic neurons has been a big challenge. Although the situation appears difficult, by now, at least 21 distinct classes of cells have been identified in the rat CA1 region using multidisciplinary approaches (Klausberger and Somogyi, 2008). Interestingly, different types of cells innervating specific extrahippocampal targets fire with distinct spike timing during network oscillation (Jinno et al., 2007). The firing pattern of GABAergic neurons projecting to both the medial septum and the subiculum (double-projection cells) is an example of the spatiotemporal requirements of long-range coordination. During theta oscillations $(4-10 \mathrm{~Hz})$, which can co-occur in hippocampal and isocortical areas (Jones and Wilson, 2005), double-projection cells fire preferentially at or after the trough of theta cycles, recorded extracellularly in stratum pyramidale, with low discharge frequencies. In contrast, the firing of $\mathrm{H}$-Sub cells in the stratum radiatum (radiatum-retrohippocampal cells) strongly increases during theta oscillation. In firing preferentially on the descending theta phase, radiatum-retrohippocampal cells are different from the local dendrite-innervating oriens-lacunosum-moleculare (O-LM), cholecystokinin-expressing and bistratified cells (Klausberger et al., 2003, 2004, 2005). During ripple oscillations (100-200 Hz), doubleprojection cells fire with a high discharge rate. This activity might lead to a suppression of the majority of cells in the medial septum and inhibit the generation of theta oscillations. Their local axons in the CA1 area innervate pyramidal cell dendrites, and cooperatively release GABA with the bistratified cells, which fire at high frequency during the ascending phase of the extracellular ripple cycle (Klausberger et al., 2004). Together, they temporally structure the excitation of the CA3 input in CA1 pyramidal dendrites at ripple frequency. The other long-range axonal arbors of double-projection cells in the subiculum also innervate dendrites of pyramidal cells and contribute to communicating the temporal structure of ripple oscillations to the subiculum, which oscillates coherently with the CA1 area (Chrobak and Buzsáki, 1996). Unlike double-projection cells, radiatum-retrohippocampal cells do not change their activity during ripples and are unlikely to contribute to coordinating this network state, indicating a different function for these neurons. The diversity of GABAergic projection cell classes in the hippocampus may result from the need to coordinate precisely the multiple activities of distributed neural circuits in different brain states and among multiple functionally related brain areas. 
Alterations in GABA-mediated signaling have been found in various psychiatric disorders (Kalueff and Nutt, 2007). For instance, reduced levels of glutamic acid decarboxylase (GAD) $67 \mathrm{mRNA}$ have been found in individuals with schizophrenia (Guidotti et al., 2000). Some postmortem studies showed that GAD activity was lower in patients with major depression compared to controls in several brain regions (Perry et al., 1977). A modern imaging study using proton magnetic resonance spectroscopy showed the reduced GABA levels in the prefrontal area of depression sufferers (Hasler et al., 2007). There is a growing body of evidence suggesting that the spatially and temporally organized synaptic inhibition mediated by specific subclasses of GABAergic neurons is impaired in mental illness (Gonzalez-Burgos and Lewis, 2008). Along these lines, it has also been postulated that cognitive and affective impairments in psychiatric disorders may be related to a failure to integrate the activity of widely spread neural circuits (Andreasen et al., 1999; Stephan et al., 2006). Interestingly, recent imaging data suggest that functional connectivity between remote regions is impaired in individuals with mental illness, such as schizophrenia (Zhou et al., 2007) and autism (Villalobos et al., 2005). Because GABAergic neurons are considered to play a critical role in the long-range fast synchronization of neural activities across brain regions (Buzsáki and Chrobak, 1995; Mann and Paulsen, 2007), these finding suggest that defects of long-range GABAergic projection system might be associated with the neurobiology of psychiatric disorders.

In summary, through fast oscillatory synchronization, distinct classes of hippocampal GABAergic neurons can contribute to the coordination of neural activity in multiple brain regions. I propose that such multiple long-range GABAergic projection systems acting in concert are of great importance in the maintenance of psychological normalcy. Understanding the characteristics of long-range GABAergic projection neurons might not only inform computational modeling of brain function, but will hopefully also make it possible to get a clue to novel treatment for psychiatric illness.

\section{ACKNOWLEDGEMENT}

The author wishes to thank Drs Peter Somogyi and Toshio Kosaka for their constructive and helpful comments on earlier versions of the manuscript. This work was partially funded by the Japanese Ministry of Education, Culture, Sports, Science and Technology (Grant-in-Aid for Scientific Research (C), No. 21500328), Uehara Memorial Foundation, Kaibara Morikazu Medical Science Promotion Foundation and Takeda Science Foundation.

\section{REFERENCES}

Alonso,A., and Köhler, C. (1982). Evidence for separate projections of hippocampal pyramidal and non-pyramidal neurons to different parts of the septum in the rat brain. Neurosci. Lett. 31, 209-214.

Andreasen, N. C., Nopoulos, P., O'Leary, D. S., Miller,D.D., Wassink, T., and Flaum, M. (1999). Defining the phenotype of schizophrenia: cognitive dysmetria and its neural mechanisms. Biol. Psychiatry 46, 908-920.

Bartus, R. T., Dean, R. L. III., Beer, B., and Lippa, A. S. (1982). The cholinergic hypothesis of geriatric memory dysfunction. Science 217, 408-414

Blasco-Ibáñez, J. M., and Freund, T. F. (1997). Distribution, ultrastructure, and connectivity of calretininimmunoreactive mossy cells of the mouse dentate gyrus. Hippocampus 7, 307-320.

Blasco-Ibáñez, J. M., MartínezGuijarro, F. J., and Freund, T. F. (1998). Enkephalin-containing interneurons are specialized to innervate other interneurons in the hippocampal CA1 region of the rat and guinea-pig. Eur. J. Neurosci. 10, 1784-1795.

Burwell, R. D., and Amaral, D. G. (1998). Cortical afferents of the perirhinal, postrhinal, and entorhinal cortices of the rat. J Comp. Neurol. 398, 179-205.

Buzsáki, G., and Chrobak, J. J. (1995). Temporal structure in spatially organized neuronal ensembles: a role for interneuronal networks. Curr. Opin. Neurobiol. 5, 504-510.
Cain, D. P., Humpartzoomian, R., and Boon, F. (2006). Retrosplenial cortex lesions impair water maze strategies learning or spatial place learning depending on prior experience of the rat. Behav. Brain Res. 170, 316-325.

Chan-Palay, V. (1987). Somatostatin immunoreactive neurons in the human hippocampus and cortex shown by immunogold/silver intensification on vibratome sections: coexistence with neuropeptide Y neurons, and effects in Alzheimer-type dementia. J. Comp. Neurol. 260, 201-223.

Chrobak, J. J., and Buzsáki, G. (1996). High-frequency oscillations in the output networks of the hippocampalentorhinal axis of the freely behaving rat. J. Neurosci. 16, 3056-3066.

DeFelipe, J. (1993). Neocortical neuronal diversity: chemical heterogeneity revealed by colocalization studies of classic neurotransmitters, neuropeptides, calcium-binding proteins, and cell surface molecules. Cereb. Cortex 3, 273-289.

DeFelipe, J., Alonso-Nanclares, L., and Arellano, J. I. (2002). Microstructure of the neocortex: comparative aspects. J. Neurocytol. 31, 299-316.

Deller, T. (1998). The anatomical organization of the rat fascia dentata: new aspects of laminar organization as revealed by anterograde tracing with Phaseolus vulgaris-Leucoagglutinin (PHAL). Anat. Embryol. (Berl.) 197, 89-103.

Deller, T., and Léránth, C. (1990). Synaptic connections of neuropeptideY (NPY) immunoreactive neurons in the hilar area of the rat hippocampus. J. Comp. Neurol. 300, 433-447.

Dragoi, G., Carpi, D., Recce, M., Csicsvari, J., and Buzsáki, G. (1999). Interactions between hippocampus and medial septum during sharp waves and theta oscillation in the behaving rat. J. Neurosci. 19, 6191-6199.

Fabri, M., and Manzoni, T. (2004). Glutamic acid decarboxylase immunoreactivity in callosal projecting neurons of cat and rat somatic sensory areas. Neuroscience 123, 557-566.

Ferraguti, F., Klausberger, T., Cobden, P., Baude, A., Roberts, J. D., Szucs, P., Kinoshita, A., Shigemoto, R., Somogyi, P., and Dalezios, Y. (2005). Metabotropic glutamate receptor 8-expressing nerve terminals target subsets of GABAergic neurons in the hippocampus. J. Neurosci. 25 10520-10536.

Freund, T. F., and Antal, M. (1988). GABA-containing neurons in the septum control inhibitory interneurons in the hippocampus. Nature 336, 170-173.

Freund, T. F., and Buzsáki, G. (1996) Interneurons of the hippocampus. Hippocampus 6, 347-470.

Freund, T. F., Hájos, N., Acsády, L., Görcs, T. J., and Katona, I. (1997). Mossy cells of the rat dentate gyrus are immunoreactive for calcitonin gene-related peptide (CGRP). Eur. J. Neurosci. 9, 1815-1830.

Frotscher, M., and Léránth, C. (1985) Cholinergic innervation of the rat hip- pocampus as revealed by choline acetyltransferase immunocytochemistry: a combined light and electron microscopic study. J. Comp. Neurol. 239, 237-246.

Fuentealba, P., Tomioka, R., Dalezios, Y., Márton, L. F., Studer, M., Rockland, K., Klausberger, T., and Somogyi, P. (2008). Rhythmically active enkephalin-expressing GABAergic cells in the CAl area of the hippocampus project to the subiculum and preferentially innervate interneurons. J. Neurosci. 28, 10017-10022.

Fujise, N., Liu, Y., Hori, N., and Kosaka, T. (1998). Distribution of calretinin immunoreactivity in the mouse dentate gyrus: II. Mossy cells, with special reference to their dorsoventral difference in calretinin immunoreactivity. Neuroscience 82, 181-200.

Gerashchenko, D., Wisor, J. P., Burns, D., Reh, R. K., Shiromani, P. J., Sakurai, T., de la Iglesia, H. O., and Kilduff, T. S. (2008). Identification of a population of sleep-active cerebral cortex neurons. Proc. Natl. Acad. Sci. USA 105, 10227-10232.

Germroth, P., Schwerdtfeger, W. K., and Buhl, E. H. (1989). GABAergic neurons in the entorhinal cortex project to the hippocampus. Brain Res. 494, 187-192.

Gold,P.E. (2003). Acetylcholine: cognitive and brain functions. Neurobiol. Learn. Mem. 80, 177.

Gonchar, Y. A., Johnson, P. B., and Weinberg, R. J. (1995). GABA-immunopositive neurons in rat neocortex 
with contralateral projections to S-I. Brain Res. 697, 27-34.

Gonzalez-Burgos, G., and Lewis, D. A. (2008). GABA neurons and the mechanisms of network oscillations: implications for understanding cortical dysfunction in schizophrenia. Schizophr. Bull. 34, 944-961.

Goodman, J.H., and Sloviter, R. S. (1992). Evidence for commissurally projecting parvalbumin-immunoreactive basket cells in the dentate gyrus of the rat. Hippocampus 2, 13-21.

Gos, T., Günther, K., Bielau, H., Dobrowolny, H., Mawrin, C., Trübner, K., Brisch, R., Steiner, J., Bernstein, H. G., Jankowski, Z., and Bogerts, B. (2009). Suicide and depression in the quantitative analysis of glutamic acid decarboxylaseimmunoreactive neuropil. J. Affect. Disord. 113, 45-55.

Guidotti, A., Auta, J., Davis, J. M., DiGiorgi-Gerevini, V., Dwivedi, Y., Grayson, D. R., Impagnatiello, F., Pandey, G., Pesold, C., Sharma, R., Uzunov, D., and Costa, E. (2000). Decrease in reelin and glutamic acid decarboxylase67 (GAD67) expression in schizophrenia and bipolar disorder: a postmortem brain study. Arch. Gen. Psychiatry 57, 1061-1069.

Gulyás, A. I., Hájos, N., Katona, I., and Freund, T. F. (2003). Interneurons are the local targets of hippocampal inhibitory cells which project to the medial septum. Eur. J. Neurosci. 17, 1861-1872.

Gulyás, A. I., Megías, M., Emri, Z., and Freund, T.F. (1999). Total number and ratio of excitatory and inhibitory synapses converging onto single interneurons of different types in the CA1 area of the rat hippocampus. J. Neurosci. 19, 10082-10097.

Gulyás, A. I., Seress, L., Tóth, K., Acsády, L., Antal, M., and Freund, T. F. (1991). Septal GABAergic neurons innervate inhibitory interneurons in the hippocampus of the macaque monkey. Neuroscience. 41, 381-390.

Hájos, N., Papp, E. C., Acsády, L., Levey, A. I., and Freund, T. F. (1998). Distinct interneuron types express $\mathrm{m} 2$ muscarinic receptor immunoreactivity on their dendrites or axon terminals in the hippocampus. Neuroscience $82,355-376$

Hasler, G., van der Veen, J.W., Tumonis, T., Meyers, N., Shen, J., and Drevets, W.C. (2007). Reduced prefrontal glutamate/ glutamine and gamma-aminobutyric acid levels in major depression determined using proton magnetic resonance spectroscopy. Arch. Gen. Psychiatry 64, 193-200.

Jinno, S., Klausberger, T., Marton, L. F., Dalezios,Y., Roberts,J.D., Fuentealba, P., Bushong, E. A., Henze, D., Buzsáki, G., and Somogyi, P. (2007). Neuronal diversity in GABAergic long-range projections from the hippocampus. J. Neurosci. 27, 8790-8804.

Jinno, S., and Kosaka, T. (2000). Colocalization of parvalbumin and somatostatin-like immunoreactivity in the mouse hippocampus: quantitative analysis with optical dissector. J. Comp. Neurol. 428, 377-388.

Jinno, S., and Kosaka, T. (2002). Immunocytochemical characterization of hippocamposeptal projecting GABAergic nonprincipal neurons in the mouse brain: a retrograde labeling study. Brain Res. 945, 219-231.

Jinno, S., and Kosaka, T. (2004). Parvalbumin is expressed in glutamatergic and GABAergic corticostriatal pathway in mice. J. Comp. Neurol. 477, 188-201.

Jinno, S., and Kosaka, T. (2006). Cellular architecture of the mouse hippocampus: a quantitative aspect of chemically defined GABAergic neurons with stereology. Neurosci. Res. 56, 229-245.

Jinno, S., and Kosaka, T. (2009). Neuronal circuit-dependent alterations in expression of two isoforms of glutamic acid decarboxylase in the hippocampus following electroconvulsive shock: a stereology-based study. Hippocampus (in press).

Jones, M. W., and Wilson, M. A. (2005). Phase precession of medial prefrontal cortical activity relative to the hippocampal theta rhythm. Hippocampus 15 , 867-873.

Kalueff, A. V., and Nutt, D. J. (2007). Role of GABA in anxiety and depression. Depress. Anxiety 24, 495-517.

Keene, C. S., and Bucci, D. J. (2009). Damage to the retrosplenial cortex produces specific impairments in spatial working memory. Neurobiol. Learn. Mem. 91, 408-414.

Klausberger, T., Magill, P. J., Marton, L., Roberts, J. D. B., Cobden, P. M., Buzsáki, G., and Somogyi, P. (2003). Brain state- and cell type-specific firing of hippocampal interneurons in vivo. Nature 421, 844-848.

Klausberger, T., Marton, L. F., Baude, A., Roberts, J. D. B., Magill, P., and Somogyi, P. (2004). Spike timing of dendrite-targeting bistratified cells during hippocampal network oscillations in vivo. Nat. Neurosci. 7, 41-47.

Klausberger, T., Marton, L. F., O'Neill, J., Huck,J.H.J.,Dalezios, Y.,Fuentealba, P., Suen, W. Y., Papp, E., Kaneko, T., Watanabe, M., Csicsvari, J., and Somogyi, P. (2005). Complementary roles of cholecystokinin- and parvalbumin-expressing GABAergic neurons in hippocampal network oscillations. J. Neurosci. 25, 9782-9793.

Klausberger, T., and Somogyi, P. (2008). Neuronal diversity and temporal dynamics: the unity of hippocampal circuit operations. Science 321, 53-57.

Köhler, C., Chan-Palay, V., and Wu, J. Y. (1984). Septal neurons containing glutamic acid decarboxylase immunoreactivity project to the hippocampal region in the rat brain Anat. Embryol. (Berl.) 169, 41-44.

Köhler, C., Eriksson, L. G., Davies, S., and Chan-Palay, V. (1987). Co-localization of neuropeptide tyrosine and somatostatin immunoreactivity in neurons of individual subfields of the rat hippocampal region. Neurosci. Lett. 78, 1-6.

Léránth, C., and Frotscher, M. (1987). Cholinergic innervation of hippocampal GAD- and somatostatin-immunoreactive commissural neurons. J. Comp. Neurol. 261, 33-47.

Liu, Y., Fujise, N., and Kosaka, T. (1996). Distribution of calretinin immunoreactivity in the mouse dentate gyrus. I. General description. Exp. Brain Res. 108, 389-403.

Losonczy, A., Zhang, L., Shigemoto, R., Somogyi, P., and Nusser,Z. (2002). Cell type dependence and variability in the short-term plasticity of EPSCs in identified mouse hippocampal interneurones. J. Physiol. 542, 193-210.

Maccaferri, G., and Lacaille, J. C. (2003). Interneuron diversity series: hippocampal interneuron classifications making things as simple as possible, not simpler. Trends Neurosci. 26 564-571.

Mann, E. O., and Paulsen, O. (2007). Role of GABAergic inhibition in hippocampal network oscillations. Trends Neurosci. 30, 343-349.

Markram, H., Toledo-Rodriguez, M., Wang, Y., Gupta, A., Silberberg, G., and $\mathrm{Wu}, \mathrm{C}$. (2004). Interneurons of the neocortical inhibitory system. Nat. Rev. Neurosci. 5, 793-807.

Mátyás, F., Freund, T. F., and Gulyás, A. I. (2004). Immunocytochemically defined interneuron populations in the hippocampus of mouse strains used in transgenic technology. Hippocampus $14,460-481$.

Miyashita, T., and Rockland, K. S. (2007). GABAergic projections from the hippocampus to the retrosplenial cortex in the rat. Eur. J. Neurosci. 26, 1193-1204.

Moore, S. J., Cooper, D. C., and Spruston, N. (2009). Plasticity of burst firing induced by synergistic activation of metabotropic glutamate and acetylcholine receptors. Neuron. 61, 287-300.

Nomura, T., Fukuda, T., Aika, Y., Heizmann, C. W., Emson, P. C., Kobayashi, T., and Kosaka, T. (1997). Laminar distribution of non-principal neurons in the rat hippocampus, with special reference to their compositional difference among layers. Brain Res. 764, 197-204.

Perry, E. K., Gibson, P. H., Blessed, G., Perry, R. H., and Tomlinson, B. E. (1977). Neurotransmitter enzyme abnormalities in senile dementia. Choline acetyltransferase and glutamic acid decarboxylase activities in necropsy brain tissue. J. Neurol. Sci. $34,247-265$.

Raisman, G. (1966). The connexions of the septum. Brain 89, 317-348.

Ramóny y Cajal, S. (1911). Histologie du Systeme Nerveux de l'Homme et es Vertebres. Paris, Malonie.

Ribak, C. E., Seress, L., Peterson, G. M., Seroogy, K. B., Fallon, J. H., and Schmued, L. C. (1986). A GABAergic inhibitory component within the hippocampal commissural pathway. J. Neurosci. 6, 3492-3498.

Sakurai, O., and Kosaka, T. (2007). Nonprincipal neurons and CA2 pyramidal cells, but not mossy cells are immunoreactive for calcitonin generelated peptide in the mouse hippocampus. Brain Res. 1186, 129-143.

Sanacora, G., and Saricicek, A. (2007). GABAergic contributions to the pathophysiology of depression and the mechanism of antidepressant action. CNS Neurol. Disord. Drug Targets 6, 127-140.

Schwerdtfeger, W. K., and Buhl, E. (1986). Various types of non-pyramidal hippocampal neurons project to the septum and contralateral hippocampus. Brain Res. 386, 146-154.

Seress, L., and Ribak, C. E. (1983). GABAergic cells in the dentate gyrus appear to be local circuit and projection neurons. Exp. Brain Res. 50, 173-182.

Shute, C. C., and Lewis, P. R. (1963). Cholinesterase-containing systems of the brain of the rat. Nature 199 , 1160-1164.

Somogyi, P., and Klausberger, T. (2005) Defined types of cortical interneurone structure space and spike timing in the hippocampus. J. Physiol. 562, 9-26.

Stephan, K. E., Baldeweg, T., and Friston, K. J. (2006). Synaptic plasticity and dysconnection in schizophrenia. Biol. Psychiatry 59, 929-939.

Takács, V. T., Freund, T. F., and Gulyás, A. I. (2008). Types and synaptic connections of hippocampal inhibitory neurons reciprocally connected with the medial septum. Eur. J. Neurosci. $28,148-164$.

Tatemoto, K., Carlquist, M., and Mutt, V. (1982). Neuropeptide Y-a novel brain peptide with structural similarities to peptide YY and pancreatic polypeptide. Nature 296, 659-660.

Tomioka, R., and Rockland, K. S. (2007). Long-distance corticocortical 
GABAergic neurons in the adult monkey white and gray matter. J. Comp. Neurol. 505, 526-538.

Tóth, K., Borhegyi, Z., and Freund, T. F. (1993). Postsynaptic targets of GABAergic hippocampal neurons in the medial septum-diagonal band of broca complex. J. Neurosci. 13, 3712-3724.

Tóth, K., and Freund, T. F. (1992). Calbindin D28k-containing nonpyramidal cells in the rat hippocampus: their immunoreactivity for GABA and projection to the medial septum. Neuroscience 49, 793-805.

Totterdell, S., and Hayes, L. (1987). Non-pyramidal hippocampal projection neurons: a light and electron microscopic study. J. Neurocytol. 16, 477-485.

van Groen, T., and Wyss, J. M. (2003). Connections of the retrosplenial granular b cortex in the rat. J. Comp. Neurol. 463, 249-263.

van Haeften, T., Wouterlood, F. G. Jorritsma-Byham, B., and Witter, M. P. (1997). GABAergic presubicular projections to the medial entorhinal cortex of the rat. J. Neurosci. 17, 862-874.

Villalobos, M. E., Mizuno, A., Dahl, B. C., Kemmotsu, N., and Müller, R. A. (2005). Reduced functional connectivity between $\mathrm{V} 1$ and inferior frontal cortex associated with visuomotor performance in autism. Neuroimage 25, 916-925.

Wang, X. J. (2002). Pacemaker neurons for the theta rhythm and their synchronization in the septohippocampal reciprocal loop. J. Neurophysiol. 87, 889-900.

Wolbers, T., and Büchel, C. (2005). Dissociable retrosplenial and hippocampal contributions to successful formation of survey representations. J. Neurosci. 25, 3333-3340.

Wyss, J. M., and van Groen, T. (1992). Connections between the retrosplenial cortex and the hippocampal formation in the rat: a review. Hippocampus 2, 1-11.

Zappone, C. A., and Sloviter, R. S. (2001) Commissurally projecting inhibitory interneurons of the rat hippocampal dentate gyrus: a colocalization study of neuronal markers and the retrograde tracer Fluoro-gold. J. Comp. Neurol. 441, 324-344.

Zhou, Y., Liang, M., Tian, L., Wang, K. Hao, Y., Liu, H., Liu, Z., and Jiang, T. (2007). Functional disintegration in paranoid schizophrenia using resting-state fMRI. Schizophr. Res. 97, 194-205.
Conflict of Interest Statement: The author declares that the research was conducted in the absence of any commercial or financial relationships that could be construed as a potential conflict of interest.

Received: 28 May 2009; paper pending published: 21 June 2009; accepted: 03 July 2009; published online: 20 July 2009.

Citation: Jinno S (2009) Structural organization of long-range GABAergic projection system of the hippocampus. Front. Neuroanat. (2009) 3:13. doi: 10.3389/neuro.05.013.2009

Copyright (c) 2009 Jinno. This is an openaccess article subject to an exclusive license agreement between the authors and the Frontiers Research Foundation, which permits unrestricted use, distribution, and reproduction in any medium, provided the original authors and source are credited. 